\title{
BMJ Open Prevalence of depression and depressive symptoms among outpatients: a systematic review and meta-analysis
}

\author{
Jinghui Wang, ${ }^{1}$ Xiaohang Wu, ${ }^{1}$ Weiyi Lai, ${ }^{1}$ Erping Long, ${ }^{1}$ Xiayin Zhang, ${ }^{1}$ \\ Wangting Li, ${ }^{1}$ Yi Zhu, ${ }^{1,2}$ Chuan Chen, ${ }^{1,2}$ Xiaojian Zhong, ${ }^{1}$ Zhenzhen Liu, ${ }^{1}$ \\ Dongni Wang, ${ }^{1}$ Haotian Lin ${ }^{1}$
}

To cite: Wang J, Wu X, Lai W, et al. Prevalence of depression and depressive symptoms among outpatients: a systematic review and meta-analysis. BMJ Open 2017;7:e017173. doi:10.1136 bmjopen-2017-017173

- Prepublication history and additional material are available. To view these files please visit the journal online (http://dx.doi. org/10.1136/bmjopen-2017017173).

JW and XW contributed equally.

Received 6 April 2017

Revised 13 June 2017

Accepted 5 July 2017

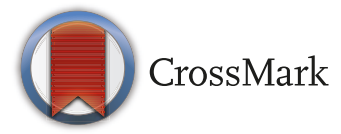

${ }^{1}$ State Key Laboratory of Ophthalmology, Zhongshan Ophthalmic Center, Sun Yat-sen University, Guangzhou, People's Republic of China

${ }^{2}$ Department of Molecular and Cellular Pharmacology, University of Miami Miller School of Medicine, Miami, Florida, USA

Correspondence to

Dr Haotian Lin;

haot.lin@hotmail.com

\section{ABSTRACT}

Objectives Depression and depressive symptoms are common mental disorders that have a considerable effect on patients' health-related quality of life and satisfaction with medical care, but the prevalence of these conditions varies substantially between published studies. The aim of this study is to conduct a systematic review and metaanalysis to provide a precise estimate of the prevalence of depression or depressive symptoms among outpatients in different clinical specialties.

Design Systematic review and meta-analysis.

Data sources and eligibility criteria The PubMed and PsycINF0, EMBASE and Cochrane Library databases were searched to identify observational studies that contained information on the prevalence of depression and depressive symptoms in outpatients. All studies included were published before January 2016. Data characteristics were extracted independently by two investigators. The point prevalence of depression or depressive symptoms was measured using validated self-report questionnaires or structured interviews. Assessments were pooled using a random-effects model. Differences in study-level characteristics were estimated by metaregression analysis. Heterogeneity was assessed using standard $\chi^{2}$ tests and the $\mathrm{I}^{2}$ statistic. The study protocol has been registered with PROSPERO under number CRD42017054738.

Results Eighty-three cross-sectional studies involving 41344 individuals were included in this study. The overall pooled prevalence of depression or depressive symptoms was $27.0 \%$ (10943/41344 individuals; $95 \% \mathrm{Cl} 24.0 \%$ to $29.0 \%$ ), with significant heterogeneity between studies $\left(p<0.0001, \tau^{2}=0.3742, l^{2}=96.7 \%\right)$. Notably, a significantly higher prevalence of depression and depressive symptoms was observed in outpatients than in the healthy controls (OR $3.16,95 \% \mathrm{Cl} 2.66$ to $3.76, \mathrm{I}^{2}=72.0 \%, \chi^{2}=25.33$ ). The highest depression/depressive symptom prevalence estimates occurred in studies of outpatients from otolaryngology clinics (53.0\%), followed by dermatology clinics (39.0\%) and neurology clinics (35.0\%). Subgroup analyses showed that the prevalence of depression and depressive symptoms in different specialties varied from $17.0 \%$ to $53.0 \%$. The prevalence of depression and depressive symptoms was higher among outpatients in developing countries than in outpatients from developed countries. Moreover, the prevalence of depression and depressive symptoms in outpatients slightly decreased

\section{Strengths and limitations of this study}

- This is the first systematic review and metaanalysis to provide a comprehensive estimate of the prevalence of depression or depressive symptoms among outpatients considering different clinical specialties.

- The information provided by this study highlights the importance of developing effective management strategies for the early identification and treatment of depression among outpatients in clinical practice.

- The substantial heterogeneity between included studies was not fully explained by the variables examined.

- The paucity of longitudinal data may decrease the generalisability of the study outcomes.

from 1996 to 2010. Regarding screening instruments, the Beck Depression Inventory led to a higher estimate of the prevalence of depression and depressive symptoms $(1316 / 4702,36.0 \%, 95 \% \mathrm{Cl} 29.0 \%$ to $44.0 \%$, $\left.\mathrm{I}^{2}=94.8 \%\right)$ than the Hospital Anxiety and Depression Scale (1003/2025, 22.0\%, 95\% Cl 12.0\% to $35.0 \%, \mathrm{I}^{2}=96.6 \%$ ).

Conclusion Our study provides evidence that a significant proportion of outpatients experience depression or depressive symptoms, highlighting the importance of developing effective management strategies for the early identification and treatment of these conditions among outpatients in clinical practice. The substantial heterogeneity between studies was not fully explained by the variables examined.

\section{INTRODUCTION}

Depression is the leading cause of disability and is a major contributor to the disease burden worldwide. The global prevalence of depression and depressive symptoms has been increasing in recent decades. ${ }^{1}$ The lifetime prevalence of depression ranges from $20 \%$ to $25 \%$ in women and $7 \%$ to $12 \%$ in men. ${ }^{2}$ Depression is a significant determinant of quality of life and survival, accounting for approximately $50 \%$ of psychiatric consultations and $12 \%$ of all hospital admissions. ${ }^{3}$ 
Notably, the prevalence of depression or depressive symptoms is higher in patients than in the general public. ${ }^{3-6}$ The underlying reasons include the illness itself and the heavy medical cost, unsatisfactory medical care service and poor doctor-patient relationship. ${ }^{78}$ Several informative systematic reviews on specific groups of outpatients have been published. For example, Mitchell et al estimated that the prevalence of depression in oncology and haematology patients was $9.6 \%-16.5 \% .^{5}$ Depression is a significant comorbidity of chronic medical disorders. The prevalence of depression in chronic medical conditions is as follows: asthma $(27 \%),{ }^{9}$ atopic dermatitis $(5 \%),{ }^{10}$ chronic obstructive pulmonary disease $(24.6 \%),{ }^{11}$ gouty arthritis (20\%), ${ }^{12}$ rheumatoid arthritis $(15 \%),{ }^{13}$ systemic lupus erythematosus $(22 \%)^{12}$ and stroke $(30 \%) .{ }^{14}$ Ismail et al conducted a meta-analysis of 57 studies and showed that the overall pooled prevalence of depression in patients with mild cognitive impairment was $32 \% .{ }^{4}$ Estimates of the prevalence of depression and depressive symptoms vary substantially between published studies, particularly with respect to specialty, patient age and residence. The inconsistency across different studies may originate from the lack of a clear definition or gold standard for the diagnosis of depression and depressive symptoms. Many previous studies have focused on depression and depressive symptoms in inpatient settings; however, mental disorders in outpatients are largely underestimated. ${ }^{6}{ }^{15}$ Depression in outpatients is associated with high indirect costs due to loss of productivity and unemployment. ${ }^{8}$ The combination of chronic medical illnesses and depression will lead to significant economic burden. ${ }^{8}$ Additionally, it is important for healthcare workers to identify mental status changes in outpatients, as mental states may affect the doctor-patient relationship and can influence patient satisfaction with medical care. ${ }^{16}$ To the best of our knowledge, no previous studies have quantitatively analysed a robust dataset with information on depression and depressive symptoms among outpatients in different clinical departments. Therefore, conducting a systematic review and meta-analysis of the depression prevalence detected during doctor visits is essential to informing efforts to prevent and treat depression and depressive symptoms among outpatients. In this study, we aimed to quantitatively summarise the prevalence of depression and depressive symptoms in different clinical departments.

\section{METHODS}

\section{Study selection}

Relevant studies published before January 2016 that described the prevalence of depression or depressive symptoms in patients from different specialties were identified using the PubMed and PsycINFO, EMBASE and Cochrane Library databases (by WJH and WXH); the selected articles were then screened by title, abstract and reference lists in collaboration with study investigators using the approach recommended by the Preferred
Reporting Items for Systematic Reviews and Meta-analyses guidelines. ${ }^{17}$ Potentially relevant papers were first identified through title and abstract searches. The full text of the retrieved articles was then assessed. The search strategy involved applying the 'explode' command to search the MeSH terms 'depression' and 'depressive symptoms' and 'outpatient*'; the combined terms were related to 'prevalence', 'cross-sectional studies' or 'controlled studies' and 'different specialties', such as 'internal medicine', 'surgical specialties' and 'paediatrics', with language restrictions (articles published in English only). More search strategy details can be found in online supplementary method 1 . The study inclusion criteria were the following: (1) articles that included patients diagnosed with a specific disease other than psychiatric disorders; (2) articles in peer-reviewed journals that involved only patients with a current degree of clinically relevant depression sufficient to warrant clinical intervention, regardless of the depression severity (mild, moderate or severe $)^{18}$; (3) studies in which depression was confirmed by validated self-report instruments or diagnostic structured interviews ${ }^{19} ;(4)$ articles with study populations who were recruited from outpatient clinics only. The exclusion criteria were as follows: (1) studies that failed to report the specific prevalence of depression, (2) studies on patients whose depression predated any other physical disorder and (3) studies on patients diagnosed with more than one psychiatric disorder (in addition to depression).

\section{Data extraction and quality assessment}

Data extraction was a multistep process based on the eligibility criteria. The following information was extracted from each study independently by two investigators (JHW and XHW) independently using a standardised form: study design, research year, country, specialty category, disease, sample size, diagnostic or screening method used and reported prevalence of depression and depressive disorders. A modified version of the Newcastle-Ottawa Scale was used to evaluate the quality of non-randomised studies. ${ }^{20}$ Studies were identified as having a low risk of bias ( $\geq 3$ points) or a high risk of bias $(<3$ points). The effect of individual studies on the overall prevalence estimate was explored by serially excluding each study in a sensitivity analysis. Additionally, two reviewers (JHW and XHW) cross-checked the reference lists of all selected articles to identify other relevant studies. All discrepancies were resolved by discussion and consensus.

\section{Statistical analysis}

As considerable heterogeneity was expected because of the multiple sources of variance, a random-effects model was used to estimate the pooled prevalence of depressive symptoms. ${ }^{21}$ Random-effect model attempted to generalise findings beyond the included studies by assuming that the selected studies are random samples from a larger population. ${ }^{22}$ The observed heterogeneity in the depression prevalence among outpatients may be attributed to differences in the assessment methods used to detect 
depression, the variation in thresholds in the different validated depression measurements, the specialties examined, the study countries, study year, patient ages and other factors. Thus, subgroup analyses were performed. Binomial proportion CIs for individual studies were calculated using the Clopper-Pearson method, which allows for asymmetry. ${ }^{23}$ Between-study heterogeneity was evaluated using standard $\chi^{2}$ tests and the $\mathrm{I}^{2}$ statistic. ${ }^{21} \mathrm{I}^{2}$ statistics were calculated to describe the percentages of total variation across studies caused by heterogeneity. A $0 \%$ value indicated no heterogeneity, and higher values represented an increase in heterogeneity. Generally, heterogeneity is categorised as $25 \%$ (low), $50 \%$ (moderate) and $75 \%$ (high). ${ }^{24}$ The results of the analysis were compared in terms of descriptive characteristics (age, specialty, study year, diagnostic method and country) using subgroup analysis and meta-regression. For models with considerable heterogeneity, a meta-regression was performed to identify the moderators that might contribute to the heterogeneity of the effect sizes. ${ }^{25}$ Publication bias of the studies was examined using funnel plots and Egger's test. ${ }^{26}$ All analyses were performed using $\mathrm{R}$ version 3.3.1 (R Foundation for Statistical Computing, Vienna, Austria) and Review Manager version 5.3 (The Cochrane Collaboration, 2015, the Nordic Cochrane Centre, Copenhagen, Denmark). Statistical tests were two-sided with a significance threshold of $p<0.05$. This study is registered with PROSPERO, number CRD42017054738.

\section{Patient involvement}

No patients eligible for screening were involved in the design and conduct of the study or involved in defining the research question or outcome measures. We have no intentions to disseminate our results to patients eligible for screening.

\section{RESULTS}

Screening the titles and abstracts resulted in 3165 articles, 110 of which were duplicates, and only 207 articles were retrieved for a detailed, full-text assessment. Of these, 83 studies fulfilled the inclusion criteria; 101 studies did not meet the eligible population criteria, 8 failed to present point prevalence data and 15 used improper outcome measures and were excluded.

Eighty-three cross-sectional studies involving a total of 41344 individuals were included in the study (figure 1). Study participants were recruited from 11 departments: 22 studies recruited patients from internal medicine clinics, 12 from primary care, 10 from neurology, 8 from dermatology, 7 from obstetrics/gynaecology, 6 from ophthalmology, 6 from oncology, 5 from infectious diseases, 4 from surgery, 3 from paediatrics and 3 from otolaryngology departments. Most (29) of the studies were conducted in Europe; 21 were performed in Asia, 19 in North America, 4 in South America, 4 in Oceania, 3 in the Middle East and 1 in Africa. Seventeen studies used the Beck Depression Inventory (BDI) to assess

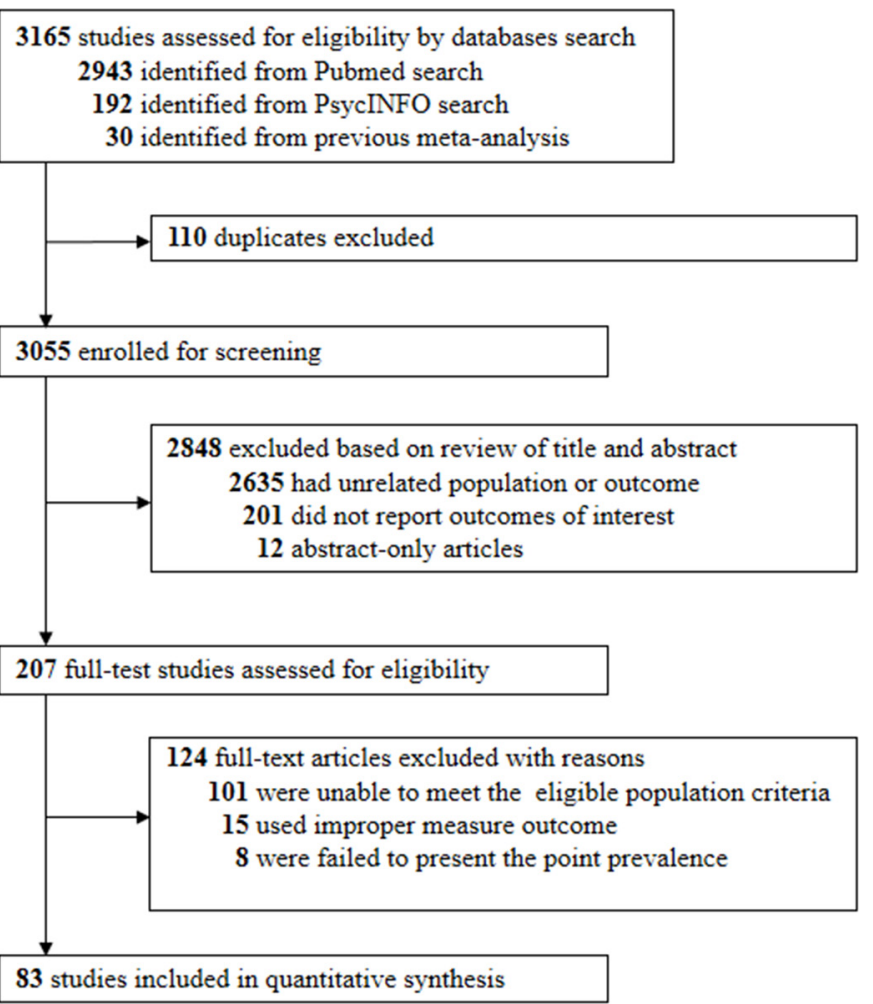

Figure 1 Flow diagram of study inclusion.

depression; 10, the Hospital Anxiety and Depression Scale (HADS); 7, the Patient Health Questionnaire; 6, the Hamilton Depression Scale, also called the Hamilton Depression Rating Scale; and 43, other methods. The full study characteristics are summarised in table 1 . The overall prevalence estimates of depression or depressive symptoms reported by the 83 studies yielded a summary prevalence of $27.0 \%$ (10943/41 344 individuals, 95\% CI $24.0 \%$ to $29.0 \%$ ), with significant between-study heterogeneity $\left(\mathrm{p}<0.0001, \tau^{2}=0.3742, \mathrm{I}^{2}=96.7 \%\right)$. Subgroup analyses by age, clinical department, study year, country and diagnosis method were conducted to explore the potential heterogeneity between studies. Of the 83 studies, the highest depression/depressive symptom prevalence estimates occurred in studies of outpatients from otolaryngology clinics $(357 / 796,53.0 \%, 95 \%$ CI $39.0 \%$ to $66.0 \%$, $\left.\mathrm{I}^{2}=79.8 \%\right)$, followed by dermatology clinics $(520 / 1558$, $39.0 \%, 95 \%$ CI $24.0 \%$ to $\left.56.0 \%, \mathrm{I}^{2}=96.9 \%\right)$ and neurology clinics $(3328 / 9280,35.0 \%, 95 \%$ CI $30.0 \%$ to $40.0 \%$, $\left.\mathrm{I}^{2}=94.4 \%\right)$. The prevalences of depression among outpatients from other specialties are summarised in figure 2. Subgroup analysis was conducted to compare studies in developed countries versus in developing countries (7788/29 208, $24.0 \%, 95 \%$ CI $21.0 \%$ to $27.0 \%, \mathrm{I}^{2}=97.0 \%$, p $<0.0001$ vs $3188 / 12050,33.0 \%, 95 \%$ CI $28.0 \%$ to $38.0 \%$, $\left.\mathrm{I}^{2}=96.8 \%, \mathrm{p}<0.0001\right)$. The prevalence of depression/ depressive symptoms in outpatients decreased from $36.0 \%$ to $24.0 \%$ from 1990 to 2010 , followed by a slight increase from 2011 to 2016. Outpatients who were younger than 30 years old showed the lowest depression prevalence, at $20.0 \%\left(170 / 797,95 \%\right.$ CI $14.0 \%$ to $28.0 \%, \mathrm{I}^{2}=81.6 \%$, 


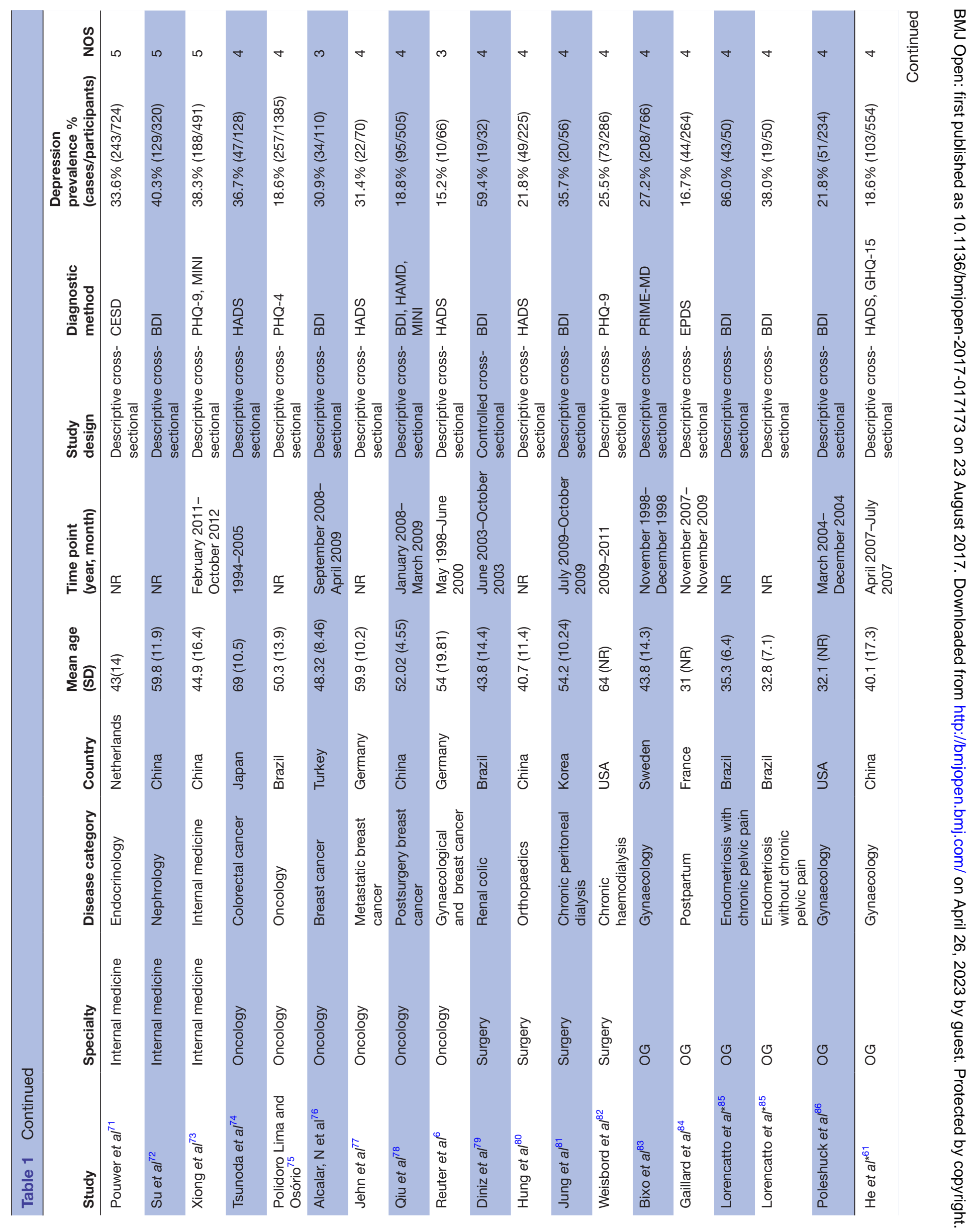




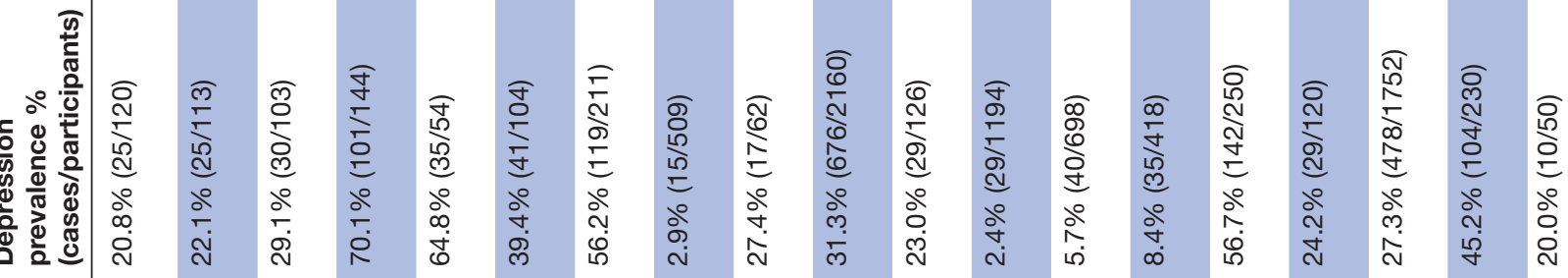

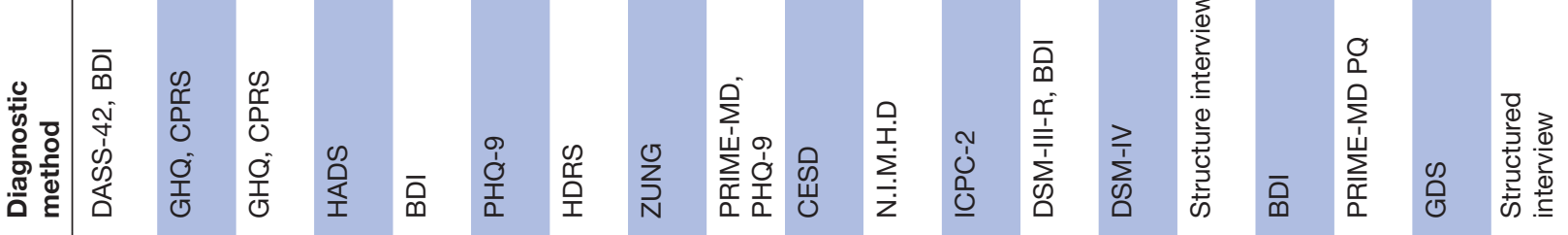

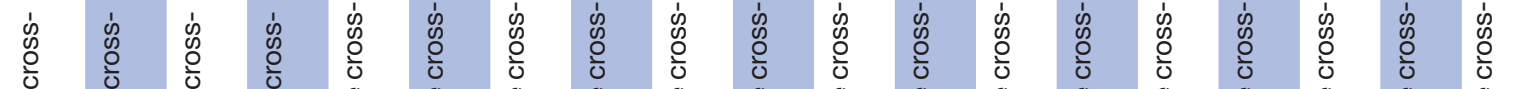

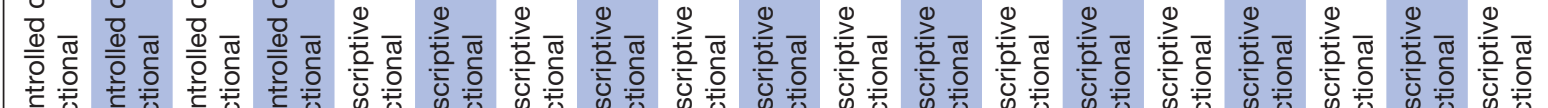

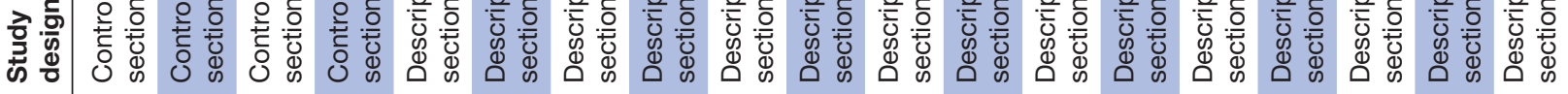

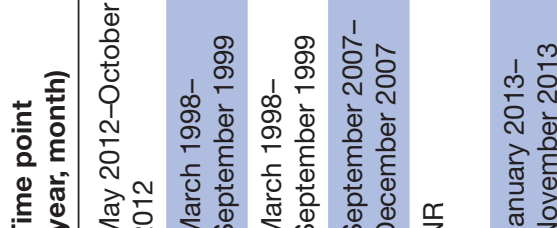

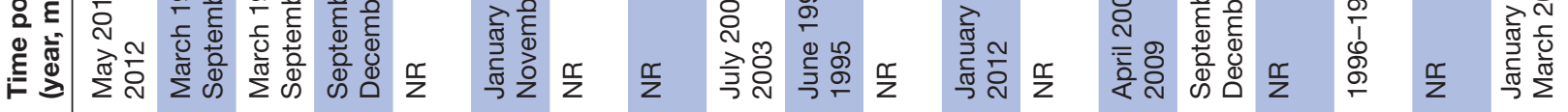

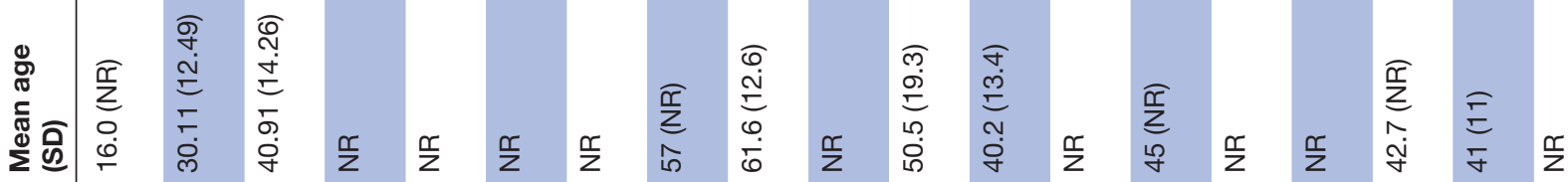

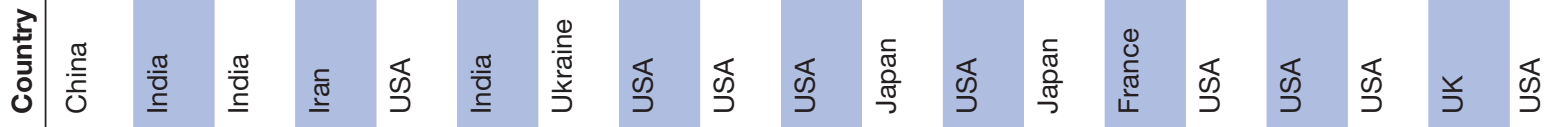

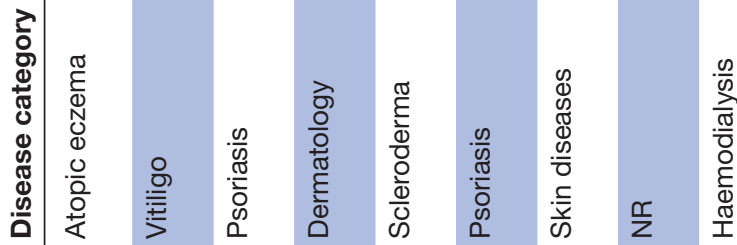

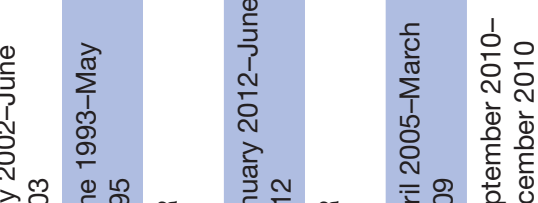

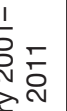




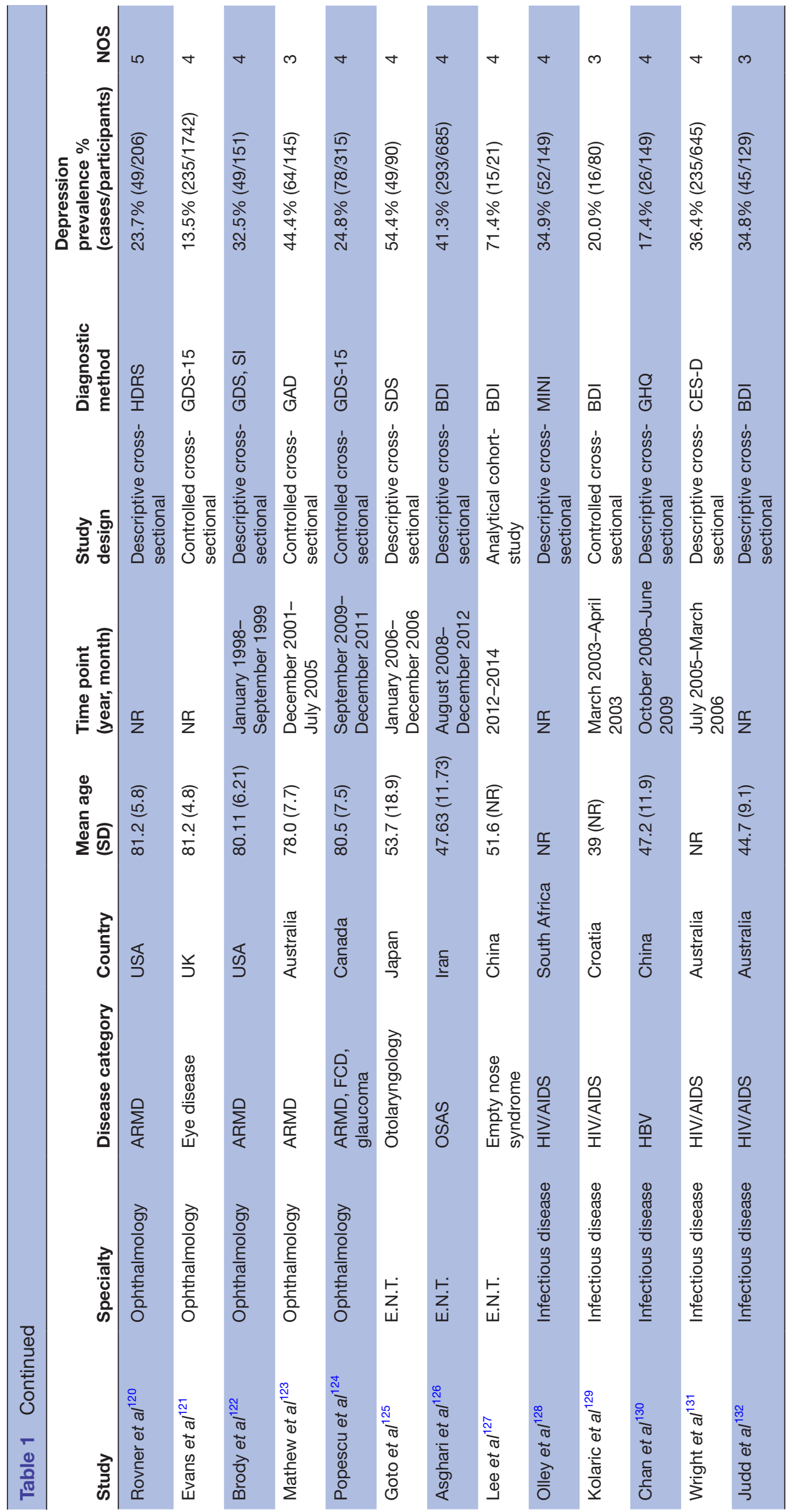

음 象

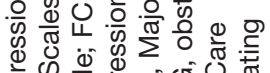

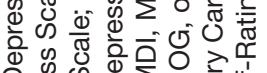

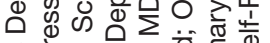

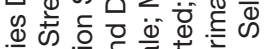

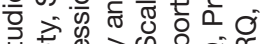

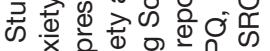

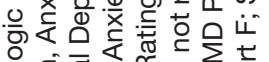

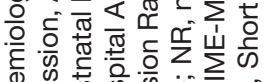

음

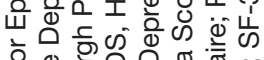

은

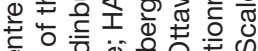

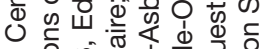

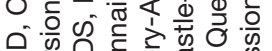

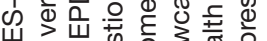

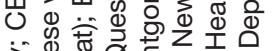

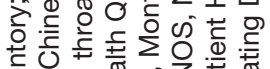

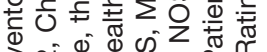

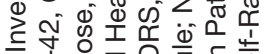

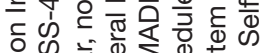

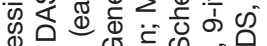

政

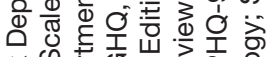

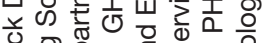

过

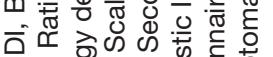

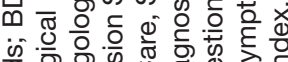

is

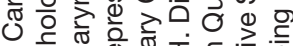

ᄃ

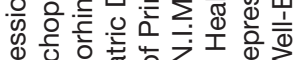

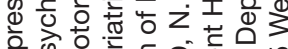

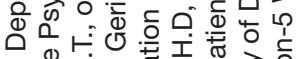

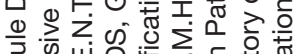

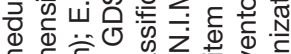

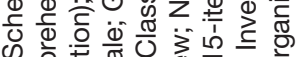

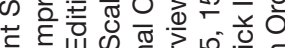

ब

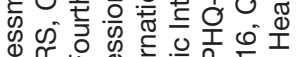

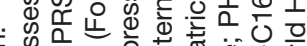

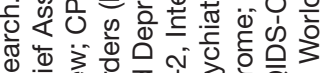

ه.

u

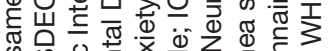

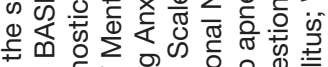

元

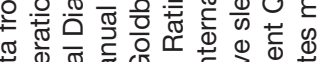

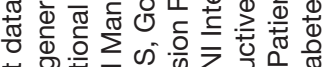

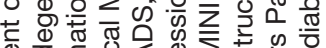

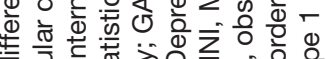

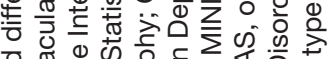

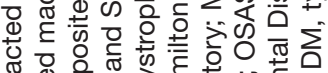

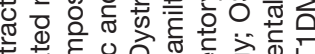

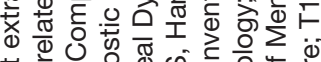

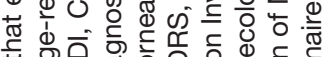

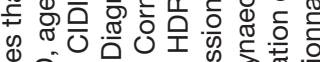

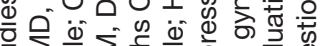

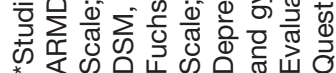




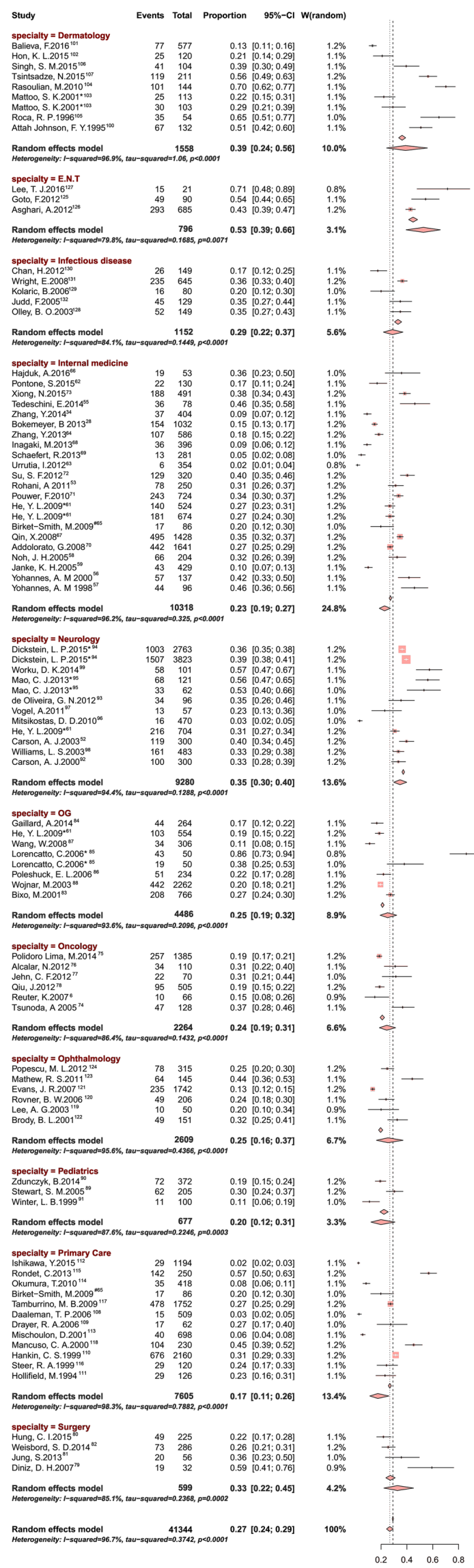

Figure 2 Forest plot of the prevalence of depression or depressive symptoms among outpatients. E.N.T., ear, nose, throat.
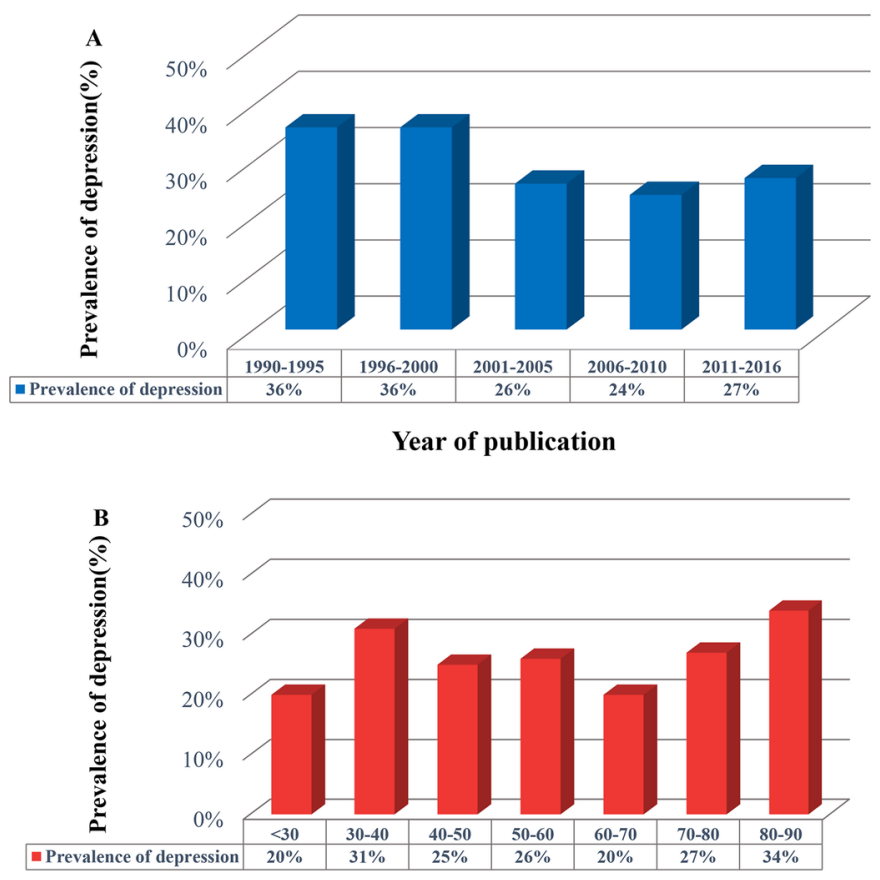

Age(year)

Figure 3 Bar graph of meta-analysis of the prevalence of depression or depressive symptoms among outpatients stratified by age and study year. (A) Prevalence of depression or depressive symptoms among outpatients stratified by year of study publication. (B) Prevalence of depression or depressive symptoms among outpatients stratified by age.

$\mathrm{p}=0.0010$ ), whereas the highest depression prevalence was reported in outpatients older than 80 years at $34.0 \%$ $\left(397 / 2128,95 \%\right.$ CI $15.0 \%$ to $69.0 \%, \mathrm{I}^{2}=96.8 \%$, $\left.\mathrm{p}<0.0001\right)$. The prevalences reported in studies stratified by year are presented in figure 3. Eight studies with healthy controls were included in a subgroup. There was a significantly higher prevalence of depression and depressive symptoms in outpatients than in healthy controls (OR 3.16, $95 \%$ CI 2.66 to $3.76, \mathrm{I}^{2}=72.0 \%, \chi^{2}=25.33$ ) (figure 4 ).

Regarding the screening instruments used, higher prevalence estimates were found among studies that used BDI $\left(1316 / 4702,36.0 \%, 95 \%\right.$ CI $29.0 \%$ to $\left.44.0 \%, \mathrm{I}^{2}=94.8 \%\right)$ compared with those that used HADS (1003/2025, $22.0 \%, 95 \%$ CI $12.0 \%$ to $35.0 \%, \mathrm{I}^{2}=96.6 \%$ ). A meta-regression analysis was conducted to evaluate the potential heterogeneity in combined subtypes to assess study year, country and specialty as sources of heterogeneity. In this analysis, country, study year and specialties represented a small amount of heterogeneity $(\mathrm{p}=0.0327,<0.05)$.

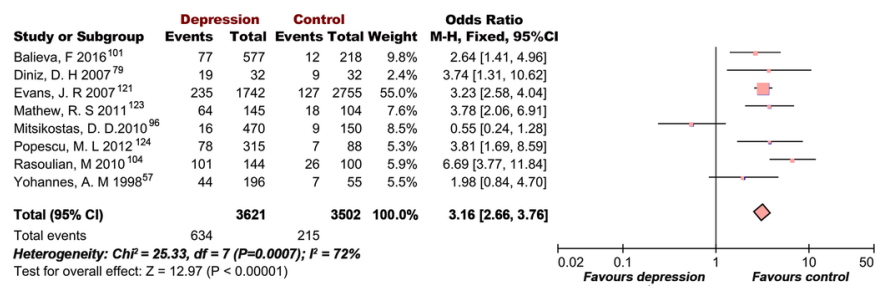

Figure 4 Forest plot of the eight studies that included control groups. 


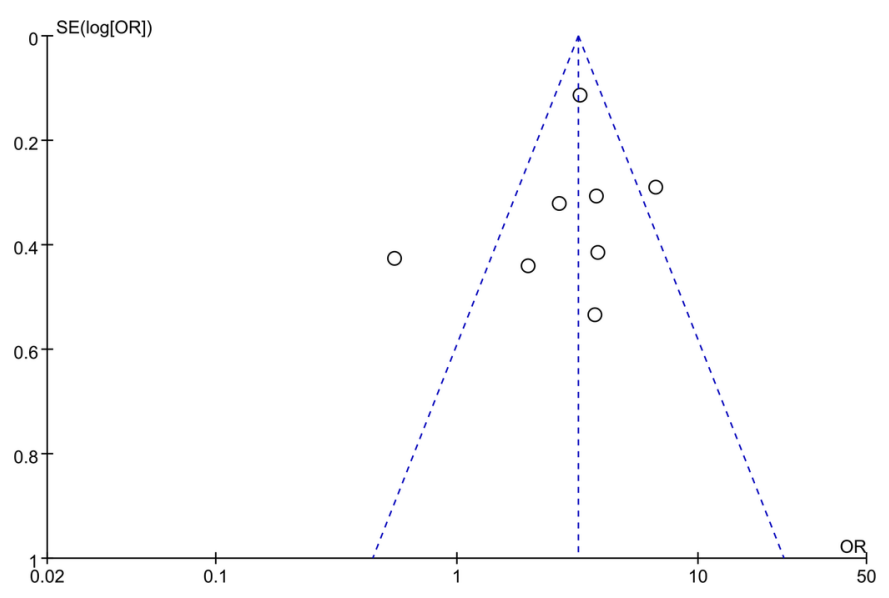

Figure 5 Funnel plots to test the publication bias of the 8 studies that included control groups. Each point represents a separate study on the indicated association. The points were distributed asymmetrically, indicating the existence of publication bias.

Funnel plots and tests indicated evidence of publication bias (Egger's test, $\mathrm{p}<0.001$, figure 5). Sensitivity analyses, in which the meta-analysis was serially repeated after excluding each study, suggested that no individual study affected the overall prevalence estimate by more than $1 \%$ (online supplementary table 1).

\section{DISCUSSION}

We performed a systematic review and meta-analysis to best estimate the prevalence of depression and depressive symptoms in different clinical departments. Overall, the prevalence of depression or depressive symptoms among outpatients was $27.0 \%$, ranging from $17.0 \%$ to $53.0 \%$ in different clinical departments. This study found that outpatients from otolaryngology clinics had the highest prevalence of depression (53.0\%). Depression was found to be an important mediator for otolaryngologic conditions such as chronic tinnitus. ${ }^{27}$ It was not surprising that dermatology ranked the second highest and $39.0 \%$ of outpatients from dermatology clinics suffered from depression. Atopic dermatitis was found to be associated with depression because the skin stigmata often causes embarrassment, low confidence and sadness. ${ }^{10} 28$ Atopic dermatitis is one of the most common dermatological disorders and was found to be associated with negative impact on the quality of life of patients, families and caregivers. ${ }^{2930}$ There is psychoneuroimmunology connection between depression and medical illness. ${ }^{31}$ The production of pro-inflammatory cytokine (eg, IL-6) was found to be higher in patients with atopic dermatitis ${ }^{32}$ and IL- 6 was found to be raised in patients with depression. ${ }^{33}$ Raised IL-6 may cause depression in patient with atopic dermatitis. This study found that $35 \%$ of outpatients from neurology clinic suffered from depression. Genetic factors and autoantibodies play an important role in causing neuropsychiatric complications including depression. ${ }^{345}$ Stroke is a common neurological disorder and causes significant health burden. ${ }^{36}$ The burden of stroke causes depression in both stroke patients and their caregivers. ${ }^{37}$ Novel rehabilitation intervention targeting at motor deficit was designed to improve functional status and quality of life of patients with stroke. ${ }^{36}$ This intervention might offer hope and reduce prevalence of depression in patients with stroke. Our study confirmed previous findings of the higher prevalence of depression or depressive symptoms in outpatients than in the general public. ${ }^{3-6}$ The prevalence of depression/depressive symptoms in outpatients slightly decreased from 1990 to 2010 . This decrease may be due to the potentially improved recognition of the illness and increased awareness for seeking help among the general public. However, this explanation has yet to be confirmed with population-based research. Depression or depressive symptoms are often overlooked during daily medical care by busy professionals without specific training in mental health, and our findings suggests that specialists should focus on patients' physical problems and their mental problems. We should enhance the awareness of mental disorders during medical works and strengthen the communication between doctors and patients. Depression is expected to vary throughout the life course, as ageing is a risk factor for the development of depression and depressive symptoms. In this study, the distribution of age-related depression had two peaks and varied in different groups. Outpatients aged 30-40 years old had a similar depression prevalence as outpatients aged 80-90 years old, with rates ranging between $30.0 \%$ and $40.0 \%$. However, previous research on the association between age and depression has shown contradictory patterns. ${ }^{38-40}$ Klerman noted a particular emergence of childhood depression and an increase in suicide attempts and death among adolescents and young adults. ${ }^{39}$ Outpatients aged 30-40 years suffering from chronic medical illnesses are at higher risk for developing depression. Depressed outpatients might develop maladaptive rumination and illness perception towards their chronic medical illness. ${ }^{41}$ Chronic medical illness may increase the risk of suicide in adult outpatients because psychosomatic complaint such as headache was found to be an important risk factor for suicide in adults. ${ }^{42}$ Yang showed that depression declined with age ${ }^{40}$ By contrast, Jorm revealed that there was no consistent pattern across studies regarding age differences in the occurrence of anxiety, depression or distress. ${ }^{38}$ Our results showed that the prevalence of depression and depressive symptoms peaked among individuals aged 30-40 years and 80-90 years, consistent with the U-shaped ageing trajectory of depression reported by a previous study. ${ }^{43}$ It has been suggested that depression reaches its highest level in elderly aged 80 years or older because physical dysfunction and low personal control add to personal and status losses. ${ }^{43}$ Risk factors of geriatric depression include poor health, brain injury, low folate and vitamin B12 and raised plasma homocysteine levels. ${ }^{44}$ The association between depression and chronic medical illnesses in elderly is due to accompanying poor self-reported health and functional 
status. ${ }^{45}$ Further, history of depression and antidepressant treatment are important risk factors for elderly suicide. ${ }^{46}$ The prevalence of depression and depressive symptoms was found to be higher $(\mathrm{p}<0.0001)$ in developing countries $(24.0 \%)$ than in developed countries $(33.0 \%)$, a greater difference and much higher than the 12-month prevalence estimates in developed $(5.5 \%)$ and developing countries $(5.9 \%)$ found in Kessler's study. ${ }^{47}$ However, a possible limitation of this finding is that Kessler's study was restricted to a small number of countries, a narrower range of severe patients and a shorter research time. ${ }^{47}$ More specifically, 13 studies from China were included in the present meta-analysis. The prevalence of depression or depressive symptoms among Chinese outpatients was $27.0 \%\left(1941 / 7194,95 \%\right.$ CI $22.0 \%$ to $\left.33.0 \%, I^{2}=95.4 \%\right)$, which fell between the prevalence observed in developing and developed countries (24.0\%-33.0\%) and consistent with China's national development.

Various factors may account for the heterogeneity in this meta-analysis. First, differences in the assessments instruments and cut-offs may have affected the diagnostic sensitivity and specificity. Modified diagnostic criteria for depression and depressive symptoms have been proposed for use in different health settings, but there is no consensus regarding the optimal diagnostic approach. Whether the existing diagnostic criteria are ideal in different health settings remains to be determined. Additionally, little attention has been devoted to the ICD (International Classification of Diseases) criteria, in which a depressive episode is defined based on the number and severity of the symptoms only. ${ }^{48}$ Second, heterogeneity between individual studies existed due to the different diagnostic methods applied in different countries. Third, the study qualities varied. For example, some studies used screening instruments with non-standard methods (eg, with cut-off scores that have not been validated) or having different thresholds in depression measurements that may increase the errors of prevalence estimates. These variations were captured in part by the modified Newcastle-Ottawa score, which assessed the risk of bias in each study.

Publication bias was assessed in this review. First, the exclusion of non-English publications likely contributed to the bias in our analysis. However, given the large number of included studies, we would not expect missed studies to significantly affect the findings. Second, because of the nature of the specialty, some studies examined the rates of depression in females only. For example, the prevalence of depression in obstetrics and gynaecology departments was $25.0 \%$, which may have caused selection bias. Also, the ageing of the population phenomenon may have a more profound impact of depression estimates in developed counties comparing with developing countries. Third, the estimates of prevalence in some specialties were based on an inadequate number of studies, which may have affected the accuracy of the overall depression prevalence. For instance, the prevalence of depression in otorhinolaryngology departments was $53.0 \%$, which was calculated using data from only three studies. Third, studies with fewer participants generally yielded more extreme prevalence estimates, further suggesting the presence of publication bias. ${ }^{49}$ The study quality is also an important factor for evaluating the presence of publication bias. However, the sensitivity analysis showed that no individual study affected the overall prevalence estimate.

\section{Limitations of this meta-analysis}

Limitations should be considered when interpreting the results of this study. First, the substantial heterogeneity between studies was not fully explained by the variables examined. For example, various disease categories, the onset of depressive episode, medical expenses, medical workers' attitudes and patients' race and gender may contribute to the risk of depressive symptoms among outpatients. Furthermore, compared with self-report scales, interview methods commonly underestimate the prevalence of psychiatric disorders. ${ }^{5}$ Second, the major update from the fourth edition of the Diagnostic and Statistical Manual of Mental Disorders (DSM-IV) to the fifth edition in 2013 may have affected the accuracy of the prevalence estimates. ${ }^{50} 51$ The severity indicator for depression and depressive symptoms was updated to be more precise, and this change may explain the increase in prevalence between 2010 and 2016. Third, the data were collected from studies that used different cross-sectional study designs, including different diseases and sample sizes. For example, in otorhinolaryngology departments, only three diseases were included in the meta-analysis, leading to low representativeness; however, given the available publications in the database, we would not expect this limitation to significantly affect the findings. Another limitation is the paucity of longitudinal data, which decreased the generalisability of the study outcomes. Therefore, high-quality studies that use cohort study designs to conduct follow-ups of depression might provide more precise outcomes. ${ }^{52}$ Fourth, using a single measure to assess depression and depressive symptom might improve the accuracy and sensitivity of the outcomes. Finally, focusing on depression alone is insufficient. Depression and depressive symptoms with other mental disorders remain an important and overlooked complication among outpatients, and this oversight calls for a more systematic approach to clinical assessment and follow-up. In conclusion, this systematic review and meta-analysis highlighted the overall high prevalence of depression and depressive symptoms, which may have long been overlooked in outpatients worldwide. Our study also provided substantial quantitative subgroup analyses that laid the foundation for researchers, clinicians and policy makers to develop effective strategies for depression management.

\section{CONCLUSION}

In summary, our study has several implications for clinical practice. First, we performed a systematic review and 
meta-analysis to estimate the prevalence of depression and depressive symptoms in different clinical departments. Second, our results suggest that more attention should be devoted to outpatient mental health, particularly in clinical departments with a high depression prevalence (eg, outpatients at otolaryngology clinics had the highest prevalence of depression $(53.0 \%)$ ). The inconsistency of the findings across different specialties regarding the prevalence of outpatients with depression could help modify and improve clinical guidelines for the evaluation and diagnosis of depression or depressive symptoms in different medical settings. Third, we identified that different screening instruments produce different estimates, and these findings may provide a reliable reference for developing an effective and unified measurement for diagnosing depression. Fourth, the substantial heterogeneity between studies was not fully explained by the variables examined.

Correction notice This article has been corrected since it was published online. The affiliation of Haotian Lin has been corrected.

Contributors HL contributed to the study design, data analysis and interpretation and manuscript preparation. JW and XW wrote the first draft of the report. JW and XW performed the literature search. WLa, EL, XZha, WLi, ZL, XZho and DW independently reassessed the integrity and accuracy of the data results. $\mathrm{HL}, \mathrm{YZ}$ and $\mathrm{CC}$ critically revised the manuscript. HL contributed to the research funding, coordinated the research and oversaw the project. All authors reviewed the manuscript for important intellectual content and approved the final manuscript.

Funding The principal investigator of this study $(\mathrm{HL})$ is currently supported by the Pearl River Scholar Program of Guangdong Province, the Outstanding Young Teacher Cultivation Projects in Guangdong Province (YQ2015006) and the Guangdong Provincial Natural Science Foundation for Distinguished Young Scholars of China (2014A030306030). The sponsors or funding organizations had no role in the design or performance of this study.

Competing interests None declared.

Provenance and peer review Not commissioned; externally peer reviewed.

Data sharing statement № additional data are available.

Open Access This is an Open Access article distributed in accordance with the Creative Commons Attribution Non Commercial (CC BY-NC 4.0) license, which permits others to distribute, remix, adapt, build upon this work non-commercially, and license their derivative works on different terms, provided the original work is properly cited and the use is non-commercial. See: http://creativecommons.org/ licenses/by-nc/4.0/

(C) Article author(s) (or their employer(s) unless otherwise stated in the text of the article) 2017. All rights reserved. No commercial use is permitted unless otherwise expressly granted.

\section{REFERENCES}

1. GBD 2015 Disease and Injury Incidence and Prevalence Collaborators. Global, regional, and national incidence, prevalence, and years lived with disability for 310 diseases and injuries, 1990-2015: a systematic analysis for the global burden of disease study 2015. Lancet 2016;388:1545-602.

2. World Health Organization. The World Health Report 2002: Reducing Risks, Promoting Healthy Life. 2002.

3. Kuo DC, Tran M, Shah AA, et al. Depression and the suicidal patient. Emerg Med Clin North Am 2015;33:765-78.

4. Ismail Z, Elbayoumi H, Fischer CE, et al. Prevalence of depression in patients with mild cognitive impairment: a systematic review and meta-analysis. JAMA Psychiatry 2017;74:58-67.

5. Mitchell AJ, Chan M, Bhatti $\mathrm{H}$, et al. Prevalence of depression, anxiety, and adjustment disorder in oncological, haematological, and palliative-care settings: a meta-analysis of 94 interview-based studies. Lancet Oncol 2011;12:160-74.
6. Reuter K, Raugust S, Marschner N, et al. Differences in prevalence rates of psychological distress and mental disorders in inpatients and outpatients with breast and gynaecological cancer. Eur $J$ Cancer Care 2007;16:222-30.

7. Wu H, Zhao X, Fritzsche K, et al. Negative illness perceptions associated with low mental and physical health status in general hospital outpatients in China. Psychol Health Med 2014;19:273-85.

8. Ho RC, Mak KK, Chua AN, et al. The effect of severity of depressive disorder on economic burden in a university hospital in Singapore. Expert Rev Pharmacoecon Outcomes Res 2013;13:549-59.

9. Lu Y, Mak KK, van Bever HP, et al. Prevalence of anxiety and depressive symptoms in adolescents with asthma: a meta-analysis and meta-regression. Pediatr Allergy Immunol 2012;23:707-15.

10. Lim VZ, Ho RC, Tee SI, et al. Anxiety and depression in patients with atopic dermatitis in a Southeast Asian tertiary dermatological centre. Ann Acad Med Singapore 2016;45:451-5.

11. Zhang MW, Ho RC, Cheung MW, et al. Prevalence of depressive symptoms in patients with chronic obstructive pulmonary disease: a systematic review, meta-analysis and meta-regression. Gen Hosp Psychiatry 2011;33:217-23.

12. Mak A, Tang CS, Chan MF, et al. Damage accrual, cumulative glucocorticoid dose and depression predict anxiety in patients with systemic lupus erythematosus. Clin Rheumatol 2011;30:795-803.

13. Ho RC, Fu EH, Chua AN, et al. Clinical and psychosocial factors associated with depression and anxiety in Singaporean patients with rheumatoid arthritis. Int J Rheum Dis 2011;14:37-47.

14. Mak KK, Kong WY, Mak A, et al. Polymorphisms of the serotonin transporter gene and post-stroke depression: a meta-analysis. $J$ Neurol Neurosurg Psychiatry 2013;84:322-8.

15. Massie MJ, Holland JC. Depression and the cancer patient. J Clin Psychiatry 1990;51:12-17.

16. Danesh DM VC, Fottler MD. Hidden workplace violence: what your nurses may not be telling you. Health Care Manag 2008.

17. Knobloch K, Yoon U, Vogt PM. Preferred reporting items for systematic reviews and meta-analyses (PRISMA) statement and publication bias. J Craniomaxillofac Surg 2011;39:91-2.

18. Anderson RJ, Freedland KE, Clouse RE, et al. The prevalence of comorbid depression in adults with diabetes: a meta-analysis. Diabetes Care 2001;24:1069-78.

19. Kerr LDK LK. Screening tools for depression in primary care. West J Med 2001;175:349-52.

20. Stang A. Critical evaluation of the Newcastle-Ottawa scale for the assessment of the quality of nonrandomized studies in metaanalyses. Eur J Epidemiol 2010;25:603-5.

21. Borenstein M, Hedges LV, Higgins JP, et al. A basic introduction to fixed-effect and random-effects models for meta-analysis. Res Synth Methods 2010;1:97-111.

22. Cheung MW, Ho RC, Lim Y, et al. Conducting a meta-analysis: basics and good practices. Int J Rheum Dis 2012;15:129-35.

23. Takkouche PK B. Confidence intervals for heterogeneity measures in meta-analysis, 2013.

24. Higgins JP, Thompson SG, Deeks JJ, et al. Measuring inconsistency in meta-analyses. BMJ 2003;327:557-60.

25. Ho RC, Cheung MW, Fu E, et al. Is high homocysteine level a risk factor for cognitive decline in elderly? A systematic review, meta-analysis, and meta-regression. Am J Geriatr Psychiatry 2011;19:607-17.

26. Sterne JA, Egger M. Funnel plots for detecting bias in metaanalysis: guidelines on choice of axis. J Clin Epidemiol 2001;54:1046-55.

27. Trevis KJ, McLachlan NM, Wilson SJ. Psychological mediators of chronic tinnitus: the critical role of depression. J Affect Disord 2016;204:234-40.

28. Chernyshov PV, Ho RC, Monti F, et al. Gender differences in self-assessed health-related quality of life in children with atopic dermatitis. J Clin Aesthet Dermatol 2016;9:19-24.

29. Ho RC, Giam YC, Ng TP, et al. The influence of childhood atopic dermatitis on health of mothers, and its impact on Asian families. Pediatr Allergy Immunol 2010;21:501-7.

30. Chernyshov PV, Jirakova A, Ho RC, et al. An international multicenter study on quality of life and family quality of life in children with atopic dermatitis. Indian J Dermatol Venereol Leprol 2013;79:52-8.

31. Ho RC, Neo LF, Chua AN, et al. Research on psychoneuroimmunology: does stress influence immunity and cause coronary artery disease? Ann Acad Med Singapore 2010;39:191-6.

32. Gharagozlou M, Farhadi E, Khaledi M, et al. Association between the interleukin 6 genotype at position -174 and atopic dermatitis. $J$ Investig Allergol Clin Immunol 2013;23:89-93. 
33. Liu Y, Ho RC, Mak A. Interleukin (IL)-6, tumour necrosis factor alpha (TNF- $\alpha$ ) and soluble interleukin-2 receptors (sIL-2R) are elevated in patients with major depressive disorder: a meta-analysis and metaregression. J Affect Disord 2012;139:230-9.

34. Ho RC, Ong H, Thiaghu $\mathrm{C}$, et al. Genetic variants that are associated with Neuropsychiatric systemic lupus erythematosus. J Rheumatol 2016;43:541-51.

35. Ho RC, Thiaghu $\mathrm{C}$, Ong $\mathrm{H}$, et al. A meta-analysis of serum and cerebrospinal fluid autoantibodies in neuropsychiatric systemic lupus erythematosus. Autoimmun Rev 2016;15:124-38.

36. Zhang MW, Yeo LL, Ho RC. Harnessing smartphone technologies for stroke care, rehabilitation and beyond. BMJ Innov 2015;1:145-50.

37. Loh AZ, Tan JS, Zhang MW, et al. The global prevalence of anxiety and depressive symptoms among caregivers of stroke survivors. $J$ Am Med Dir Assoc 2017;18:111-6.

38. Jorm AF. Does old age reduce the risk of anxiety and depression? A review of epidemiological studies across the adult life span. Psycho Med 2000;30:11-22.

39. Klerman GL. The current age of youthful melancholia. Evidence for increase in depression among adolescents and young adults. $\mathrm{Br} \mathrm{J}$ Psychiatry 1988;152:4-14.

40. Yang Y. Is old age depressing? Growth trajectories and cohort variations in late-life depression. J Health Soc Behav 2007;48:16-32.

41. Lu Y, Tang C, Liow CS, et al. A regressional analysis of maladaptive rumination, illness perception and negative emotional outcomes in Asian patients suffering from depressive disorder. Asian J Psychiatr 2014;12:69-76.

42. Choo C, Diederich J, Song I, et al. Cluster analysis reveals risk factors for repeated suicide attempts in a multi-ethnic Asian population. Asian J Psychiatr 2014;8:38-42.

43. Mirowsky J, Ross CE. Age and depression. J Health Soc Behav 1992;33:187.

44. Heok KE, Ho R. The many faces of geriatric depression. Curr Opin Psychiatry 2008;21:540-5.

45. Niti M, Ng TP, Kua EH, et al. Depression and chronic medical illnesses in Asian older adults: the role of subjective health and functional status. Int J Geriatr Psychiatry 2007;22:1087-94.

46. Ho RC, Ho EC, Tai BC, et al. Elderly suicide with and without a history of suicidal behavior: implications for suicide prevention and management. Arch Suicide Res 2014;18:363-75

47. Kessler RC, Birnbaum HG, Shahly V, et al. Age differences in the prevalence and co-morbidity of DSM-IV major depressive episodes: results from the WHO World Mental Health Survey Initiative. Depress Anxiety 2010;27:351-64.

48. The ICD-10 classification of mental and behavioural disorders: clinical descriptions and diagnostic guidelines. Geneva: World Health Organization, 1992.

49. Mata DA, Ramos MA, Bansal N, et al. Prevalence of depression and depressive symptoms among resident physicians: a systematic review and meta-analysis. JAMA 2015;314:2373-83.

50. American Psychiatric Association. Diagnostic and statistical manual of mental disorders (DSM-IV). 4th edn. Washington: American Psychiatric Press, 1994.

51. American Psychiatric Association. Diagnostic and statistical manual of mental disorders (DSM-V). 5th edn. Washington: American Psychiatric Press, 2013.

52. Carson AJ, Postma K, Stone J, et al. The outcome of depressive disorders in neurology patients: a prospective cohort study. $J$ Neurol Neurosurg Psychiatry 2003;74:893-6.

53. Rohani A, Akbari V, Zarei F. Anxiety and depression symptoms in chest pain patients referred for the exercise stress test. Heart Views 2011;12:161-4.

54. Bokemeyer B, Hardt J, Hüppe D, et al. Clinical status, psychosocial impairments, medical treatment and health care costs for patients with inflammatory bowel disease (IBD) in Germany: an online IBD registry. J Crohns Colitis 2013;7:355-68.

55. Tedeschini E, Pingani L, Simoni E, et al. Correlation of articular involvement, skin disfigurement and unemployment with depressive symptoms in patients with systemic sclerosis: a hospital sample. Int $J$ Rheum Dis 2014;17:186-94.

56. Yohannes AM, Baldwin RC, Connolly MJ. Depression and anxiety in elderly outpatients with chronic obstructive pulmonary disease: prevalence, and validation of the BASDEC screening questionnaire. Int J Geriatr Psychiatry 2000;15:1090-6.

57. Yohannes AM, Roomi J, Baldwin RC, et al. Depression in elderly outpatients with disabling chronic obstructive pulmonary disease. Age Ageing 1998;27:155-60.

58. Noh JH, Park JK, Lee HJ, et al. Depressive symptoms of type 2 diabetics treated with insulin compared to diabetics taking oral anti-diabetic drugs: a Korean study. Diabetes Res Clin Pract 2005;69:243-8

59. Janke KH, Klump B, Gregor M, et al. Determinants of life satisfaction in inflammatory bowel disease. Inflamm Bowel Dis 2005;11:272-86.

60. Zhang Y, Fritzsche K, Leonhart R, et al. Dysfunctional illness perception and illness behaviour associated with high somatic symptom severity and low quality of life in general hospital outpatients in China. J Psychosom Res 2014;77:187-95.

61. He YL, Ma H, Zhang L, et al. [A cross-sectional survey of the prevalence of depressive-anxiety disorders among general hospital outpatients in five cities in China]. Zhonghua Nei Ke Za Zhi 2009;48:748-51.

62. Pontone S, Ridola L, Marianetti M, et al. Endoscopic findings and psychometric abnormalities: what is the relationship in upper endoscopic outpatients? Clin Ter 2015;166:238-43.

63. Urrutia I, Aguirre U, Pascual S, et al. Impact of anxiety and depression on disease control and quality of life in asthma patients. $J$ Asthma 2012;49:201-8.

64. Zhang $\mathrm{Y}$, Ting $\mathrm{R}$, Lam M, et al. Measuring depressive symptoms using the Patient Health Questionnaire-9 in Hong Kong Chinese subjects with type 2 diabetes. J Affect Disord 2013;151:660-6.

65. Birket-Smith $\mathrm{M}$, Hansen $\mathrm{BH}$, Hanash JA, et al. Mental disorders and general well-being in cardiology outpatients--6-year survival. $J$ Psychosom Res 2009;67:5-10.

66. Hajduk A, Nowicka-Sauer K, Smoleńska Ż, et al. Prevalence and correlates of suicidal thoughts in patients with neuropsychiatric lupus. Lupus 2016;25:185-92.

67. Qin X, Wang W, Jin Q, et al. Prevalence and rates of recognition of depressive disorders in internal medicine outpatient departments of 23 general hospitals in Shenyang, China. J Affect Disord 2008;110:46-54.

68. Inagaki M, Ohtsuki T, Yonemoto $\mathrm{N}$, et al. Prevalence of depression among outpatients visiting a general internal medicine polyclinic in rural Japan. Gen Hosp Psychiatry 2013;35:286-90.

69. Schaefert R, Höner C, Salm F, et al. Psychological and behavioral variables associated with the somatic symptom severity of general hospital outpatients in China. Gen Hosp Psychiatry 2013;35:297-303

70. Addolorato G, Mirijello A, D'Angelo C, et al. State and trait anxiety and depression in patients affected by gastrointestinal diseases: psychometric evaluation of 1641 patients referred to an internal medicine outpatient setting. Int J Clin Pract 2008;62:1063-9.

71. Pouwer F, Geelhoed-Duijvestijn PH, Tack CJ, et al. Prevalence of comorbid depression is high in out-patients with type 1 or type 2 diabetes mellitus. Results from three out-patient clinics in the Netherlands. Diabet Med 2010;27:217-24.

72. Su SF, Ng HY, Huang TL, et al. Survey of depression by Beck Depression Inventory in uremic patients undergoing hemodialysis and hemodiafiltration. Ther Apher Dial 2012;16:573-9.

73. Xiong N, Fritzsche K, Wei J, et al. Validation of patient health questionnaire (PHQ) for major depression in Chinese outpatients with multiple somatic symptoms: a multicenter cross-sectional study. J Affect Disord 2015;174:636-43.

74. Tsunoda A, Nakao K, Hiratsuka K, et al. Anxiety, depression and quality of life in colorectal cancer patients. Int $J$ Clin Oncol 2005;10:411-7.

75. Polidoro Lima M, Osório FL. Indicators of psychiatric disorders in different oncology specialties: a prevalence study. J Oncol 2014:2014:1-7.

76. Alcalar N, Ozkan S, Kucucuk S, et al. Association of coping style, cognitive errors and cancer-related variables with depression in women treated for breast cancer. Jpn J Clin Oncol 2012;42:940-7.

77. Jehn CF, Flath B, Strux A, et al. Influence of age, performance status, cancer activity, and IL-6 on anxiety and depression in patients with metastatic breast cancer. Breast Cancer Res Treat 2012;136:789-94.

78. Qiu J, Yang M, Chen W, et al. Prevalence and correlates of major depressive disorder in breast cancer survivors in Shanghai, China. Psychooncology 2012;21:1331-7.

79. Diniz DH, Blay SL, Schor N. Anxiety and depression symptoms in recurrent painful renal lithiasis colic. Braz J Med Biol Res 2007;40:949-55.

80. Hung Cl, Liu CY, Fu TS. Depression: An important factor associated with disability among patients with chronic low back pain. Int $J$ Psychiatry Med 2015;49:187-98.

81. Jung S, Lee YK, Choi SR, et al. Relationship between cognitive impairment and depression in dialysis patients. Yonsei Med $\mathrm{J}$ 2013;54:1447-53.

82. Weisbord SD, Mor MK, Sevick MA, et al. Associations of depressive symptoms and pain with dialysis adherence, health resource 
utilization, and mortality in patients receiving chronic hemodialysis. Clin J Am Soc Nephrol 2014;9:1594-602.

83. Bixo M, Sundström-Poromaa I, Björn I, et al. Patients with psychiatric disorders in gynecologic practice. Am J Obstet Gynecol 2001;185:396-402.

84. Gaillard A, Le Strat $Y$, Mandelbrot $L$, et al. Predictors of postpartum depression: prospective study of 264 women followed during pregnancy and postpartum. Psychiatry Res 2014;215:341-6.

85. Lorençatto C, Petta CA, Navarro MJ, et al. Depression in women with endometriosis with and without chronic pelvic pain. Acta Obstet Gynecol Scand 2006;85:88-92.

86. Poleshuck EL, Giles DE, Tu X. Pain and depressive symptoms among financially disadvantaged women's health patients. J Womens Health 2006;15:182-93.

87. Wang W, Xu B, Luan R, et al. [Study of depressive and anxiety disorder in menopausal gynecologic outpatients in three Chinese cities]. Wei Sheng Yan Jiu 2008;37:211-3.

88. Wojnar M, Dród W, Araszkiewicz A, et al. Assessment and prevalence of depression in women 45-55 years of age visiting gynecological clinics in Poland: screening for depression among midlife gynecologic patients. Arch Womens Ment Health 2003:6:193-201.

89. Stewart SM, Rao U, Emslie GJ, et al. Depressive symptoms predict hospitalization for adolescents with type 1 diabetes mellitus. Pediatrics 2005;115:1315-9.

90. Zduńczyk B, Sendela J, Szypowska A. High prevalence of depressive symptoms in well-controlled adolescents with type 1 diabetes treated with continuous subcutaneous insulin infusion Diabetes Metab Res Rev 2014;30:333-8.

91. Winter Y, Epifanova-Bertschi N, Sankowski R, et al. Health-related quality of life and its determinants in the urban Russian population with major depressive disorder: a cross-sectional study. Int $J$ Psychiatry Med 2012;43:35-49.

92. Carson AJ, Ringbauer B, MacKenzie L, et al. Neurological disease, emotional disorder, and disability: they are related: a study of 300 consecutive new referrals to a neurology outpatient department. $J$ Neurol Neurosurg Psychiatry 2000;68:202-6.

93. de Oliveira GN, Kummer A, Marchetti RL, et al. A critical and descriptive approach to interictal behavior with the Neurobehavior Inventory (NBI). Epilepsy Behav 2012;25:334-40.

94. Dickstein LP, Viguera AC, Nowacki AS, et al. Thoughts of death and self-harm in patients with epilepsy or multiple sclerosis in a tertiary care center. Psychosomatics 2015;56:44-51.

95. Mao CJ, Chen JP, Hu WD, et al. [Depression associated with movement disorders]. Zhonghua Yi Xue Za Zhi 2013;93:26-9.

96. Mitsikostas DD, Thomas AM. Comorbidity of headache and depressive disorders. Cephalalgia 1999;19:211-7.

97. Vogel A, Bhattacharya S, Larsen JL, et al. Do subjective cognitive complaints correlate with cognitive impairment in systemic lupus erythematosus? A Danish outpatient study. Lupus 2011;20:35-43

98. Williams LS, Jones WJ, Shen J, et al. Prevalence and impact of depression and pain in neurology outpatients. J Neurol Neurosurg Psychiatry 2003;74:1587-9.

99. Worku DK, Yifru YM, Postels DG, et al. Prevalence of depression in Parkinson's disease patients in Ethiopia. J Clin Mov Disord 2014;1:10

100. Attah Johnson FY, Mostaghimi H. Co-morbidity between dermatologic diseases and psychiatric disorders in Papua New Guinea. Int J Dermatol 1995;34:244-8.

101. Balieva F, Lien L, Kupfer J, et al. Are common skin diseases among norwegian dermatological outpatients associated with psychological problems compared with controls? An observational study. Acta Derm Venereol 2016;96:227-31.

102. Hon KL, Pong NH, Poon TC, et al. Quality of life and psychosocial issues are important outcome measures in eczema treatment. $J$ Dermatolog Treat 2015;26:83-9.

103. Mattoo SK, Handa S, Kaur I, et al. Psychiatric morbidity in vitiligo and psoriasis: a comparative study from India. J Dermatol 2001;28:424-32.

104. Rasoulian M, Ebrahimi AA, Zare M, et al. Psychiatric morbidity in dermatological conditions. Int J Psychiatry Clin Pract 2010;14:18-22.

105. Roca RP, Wigley FM, White B. Depressive symptoms associated with scleroderma. Arthritis Rheum 1996;39:1035-40.

106. Singh SM, Narang T, Dogra S, et al. Screening for depressive disorders in outpatients with mild to moderate psoriasis: a study from North India. Indian J Dermatol Venereol Leprol 2015;81:148-50.
107. Tsintsadze N, Beridze L, Tsintsadze N, et al. Psychosomativ aspects in patients with dermatologic disease. Georgian Med News 2015:70-5.

108. Daaleman TP, Kaufman JS. Spirituality and depressive symptoms in primary care outpatients. South Med J 2006;99:1340-4.

109. Drayer RA, Piraino B, Reynolds CF, et al. Characteristics of depression in hemodialysis patients: symptoms, quality of life and mortality risk. Gen Hosp Psychiatry 2006;28:306-12.

110. Hankin CS, Spiro A, Miller DR, et al. Mental disorders and mental health treatment among U.S. Department of Veterans Affairs outpatients: the Veterans Health Study. Am J Psychiatry 1999;156:1924-30.

111. Hollifield M, Katon W, Morojele N. Anxiety and depression in an outpatient clinic in Lesotho, Africa. Int J Psychiatry Med 1994:24:179-88.

112. Ishikawa $\mathrm{Y}$, Takeshima T, Mise J, et al. Physical symptoms in outpatients with psychiatric disorders consulting the general internal medicine division at a Japanese university hospital. Int $J$ Gen Med 2015;8:261-6.

113. Michalski D, Liebig S, Thomae E, et al. Anxiety, depression and impaired health-related quality of life are therapeutic challenges in patients with multiple sclerosis. Ment IIIn 2010;2:5.

114. Okumura T, Tanno S, Ohhira M, et al. Characteristics in patients with headache in an outpatient clinic in Japan. Asia Pac Fam Med 2010;9:10.

115. Rondet C, Cornet P, Kaoutar B, et al. Depression prevalence and primary care among vulnerable patients at a free outpatient clinic in Paris, France, in 2010: results of a cross-sectional survey. BMC Fam Pract 2013;14:151.

116. Steer RA, Cavalieri TA, Leonard DM, et al. Use of the Beck Depression Inventory for primary care to screen for major depression disorders. Gen Hosp Psychiatry 1999;21:106-11.

117. Tamburrino MB, Lynch DJ, Nagel RW, et al. Primary care evaluation of mental disorders (PRIME-MD) screening for minor depressive disorder in primary care. Prim Care Companion J Clin Psychiatry 2009;11:339-43.

118. Mancuso CA, Peterson MG, Charlson ME. Effects of depressive symptoms on health-related quality of life in asthma patients. J Gen Intern Med 2000;15:301-10.

119. Lee AG, Beaver HA, Jogerst G, et al. Screening elderly patients in an outpatient ophthalmology clinic for dementia, depression, and functional impairment. Ophthalmology 2003;110:651-7.

120. Rovner BW, Casten RJ, Hegel MT, et al. Minimal depression and vision function in age-related macular degeneration. Ophthalmology 2006;113:1743-7.

121. Evans JR, Fletcher AE, Wormald RP. Depression and anxiety in visually impaired older people. Ophthalmology 2007;114:283-8.

122. Brody BL, Gamst AC, Williams RA, et al. Depression, visual acuity, comorbidity, and disability associated with age-related macular degeneration. Ophthalmology 2001;108:1893-900.

123. Mathew RS, Delbaere K, Lord SR, et al. Depressive symptoms and quality of life in people with age- related macular degeneration. Ophthalmic Physiol Opt 2011;31:375-80.

124. Popescu ML, Boisjoly H, Schmaltz H, et al. Explaining the relationship between three eye diseases and depressive symptoms in older adults. Invest Ophthalmol Vis Sci 2012;53:2308-13.

125. Goto F, Tsutsumi T, Oishi N, et al. Hidden depression in otolaryngology patients with medically unexplained symptoms. Gen Hosp Psychiatry 2012;34:206-8.

126. Asghari A, Mohammadi F, Kamrava SK, et al. Severity of depression and anxiety in obstructive sleep apnea syndrome. Eur Arch Otorhinolaryngol 2012;269:2549-53.

127. Lee TJ, Fu CH, Wu CL, et al. Evaluation of depression and anxiety in empty nose syndrome after surgical treatment. Laryngoscope 2016;126:1284-9

128. Olley BO, Gxamza F, Seedat S, et al. Psychopathology and coping in recently diagnosed HIV/AIDS patients--the role of gender. $S$ Afr Med J 2003;93:928-31.

129. Kolarić $\mathrm{B}$, Tesić $\mathrm{V}$, Ivanković $\mathrm{D}$, et al. Prevalence of moderate and severe depression among Croatian patients infected with human immunodeficiency virus. Coll Antropol 2006;30(Suppl 2):85-8.

130. Chan H, Yu CS, Li SY. Psychiatric morbidity in Chinese patients with chronic hepatitis B infection in a local infectious disease clinic. East Asian Arch Psychiatry 2012;22:160-8.

131. Wright E, Brew B, Arayawichanont A, et al. Neurologic disorders are prevalent in HIV-positive outpatients in the Asia-Pacific region. Neurology 2008;71:50-6.

132. Judd F, Komiti $A$, Chua $P$, et al. Nature of depression in patients with HIV/AIDS. Aust N Z J Psychiatry 2005;39:826-32. 